\title{
Esperança: tarefa necessária e urgente
}

Hope: a necessary and urgent task

\section{Luis Duarte Vieira}

duarteluis05@gmail.com

Doutorando em Ensino de Ciências e

Matemática pelo Programa de Pós-

Graduação em Ensino de Ciências e

Matemática da Universidade de Passo

Fundo.

\section{Maicon André Malacarne \\ maico.malacarne@gmail.com}

Padre da diocese de Erexim/RS. Especialista em juventude no mundo contemporâneo pela FAJE. Bacharel em Filosofia pelo IFIBE e em Teologia pelo ITEPA.

\section{Cleci Teresinha Werner da Rosa cwerner@upf.br \\ Docente e coordenadora do Programa de \\ Pós-Graduação em Ensino de Ciências e \\ Matemática da Universidade de Passo \\ Fundo.}

\section{Resumo}

Em tempos de tantas mortes e perdas, neste contexto da pandemia, a esperança é uma tarefa necessária e urgente. Neste artigo, mediante pesquisa bibliográfica, objetiva-se apresentar algumas contribuições de Paulo Freire na reflexão sobre a tarefa da Escola em educar para a esperança. Conclui-se que a Escola pode ajudar a derrotar o programa da desesperança.

Palavras-chave: Paulo Freire; esperança; educação.

\begin{abstract}
In times of so many deaths and losses, in this context of the pandemic, hope is a necessary and urgent task. Therefore, in this article, through bibliographic research, the objective is to present some contributions by Paulo Freire in reflecting on the imperative task of the school in educating for hope. It is concluded that the school can help to defeat the program of hopelessness.
\end{abstract}

Keywords: Paulo Freire; hope; education. 


\section{Introdução}

Toda a humanidade vive um tempo marcado pelos efeitos da pandemia da Covid-19, que tem ceifado milhares de vidas diariamente e, no Brasil, parece piorar a cada dia. Ao discorrer sobre a realidade brasileira, Eliane Brum, já em 2017 e, portanto, em outro contexto, dizia que:

O sobressalto encarnou-se nos dias. Não é mais inerente ao cotidiano, mas o próprio cotidiano. Temos vivido no Brasil (e acredito que em boa parte do mundo) aos espasmos. Um espasmo, outro espasmo, mais um espasmo. A cada noite, dormimos (ou tentamos dormir) sem saber o que acontecerá no país. (...). Não há mais como imaginar o dia de amanhã. Às vezes, não dá para imaginar a hora seguinte. $\mathrm{O}$ sobressalto tece a experiência - tanto a coletiva, a maneira como estamos com os outros, como a individual, nosso modo de estar consigo mesmos. Acusamos o impacto nas nossas vísceras, o sentimos na ansiedade misturada aos goles de café, mas não somos capazes de dimensionar. É assim que a exceção vai se infiltrando nas horas - e também nas almas. E é assim também que ela mina a nossa resistência. Como persistir, então? (Brum, 2017)

Brum tem razão ao afirmar que não temos como dimensionar os impactos sobre nossas vidas e que vamos vivendo de "sobressaltos". E quando falamos da pandemia da Covid-19, que ainda está em curso, parece que essa afirmação é ainda mais real e mais dura. A cada dia a vacinação segue ocorrendo, mas de modo muito lento, enquanto o número de mortos cresce rapidamente.

Além das vidas ceifadas pela pandemia, essa doença mexeu com os hábitos a vida das pessoas porque exigiu o distanciamento social e o fim de aglomerações. Com isso, a educação foi profundamente afetada. As aulas presenciais foram suspensas e iniciou-se, com muitos limites, o ensino remoto. Transcorrido mais de um ano desde a suspensão das aulas, algumas redes de ensino, públicas e privadas, retomaram as atividades presenciais enquanto outras seguem com as aulas remotas. Muito se pode afirmar sobre os desafios, impactos e consequências da pandemia ou do ensino remoto, mas nesse artigo dialoga-se sobre “(...) a urgente e necessária" tarefa da esperança, que é, de acordo com Freire, "um imperativo existencial e histórico" (2019, p.14). Freire ainda salienta que "a esperança é um condimento indispensável à experiência histórica. Sem ela, não haveria História, mas puro determinismo" (1996, p.31). A esperança é necessária e urgente, sobretudo em tempos tão sofridos como esse de pandemia.

Ora, sendo assim, ela é tarefa de todos que acreditam em um mundo melhor e na escola como um lugar essencial na vida de todos e todas. Nesse contexto, este trabalho busca 
VIEIRA, Luis Duarte; MALACARNE, Maicon André; ROSA, Cleci Teresinha Werner da; Esperança: tarefa

responder a seguinte questão: "qual a contribuição de Paulo Freire para a reflexão da esperança como uma tarefa da educação?”. Posta essa problemática, o artigo vai apresentar algumas colaborações de Paulo Freire na reflexão sobre a importante tarefa da escola em educar para a esperança.

Essa reflexão justifica-se pelo contexto social que se vive no país. A esperança é fundamental, essencial e vital. Além desse aspecto, salientamos que academicamente esse artigo justifica-se por apresentar algumas contribuições de Paulo Freire para que a educação seja geradora de esperança, o que ajudará educadores e escolas a assumirem sua parte nessa demanda urgente.

\section{Metodologia}

Com o propósito de elencar algumas contribuições de Paulo Freire para que a educação aponte na direção da "urgente e necessária tarefa da esperança" (Freire, 2019), realizou-se uma pesquisa qualitativa e bibliográfica.

Bogdan e Biklen identificam a pesquisa qualitativa como aquela em que "os dados recolhidos são em forma de palavras ou imagens e não de números" (1994, p.48) e os "investigadores interessam-se mais pelo processo do que simplesmente pelos resultados ou produtos" (p.49). A definição dada por esses teóricos fundamenta a escolha desse tipo de pesquisa para a construção deste artigo. $\mathrm{Na}$ escrita dessa reflexão sobre a esperança como uma tarefa necessária e urgente para a educação, fez-se a opção pelo processo. Além desse elemento, ressalta-se que nesse trabalho os dados foram reunidos em formas de palavras, reflexões.

Gil define a pesquisa bibliográfica como aquela que "é desenvolvida com base em material já elaborado, constituído principalmente de livros e artigos científicos" (2002, p.44). Partindo dessa definição, este trabalho assume esse tipo de pesquisa porque analisou, sobretudo, as obras Pedagogia da Esperança e Pedagogia da Autonomia, ambas de Paulo Freire.

\section{Resultados}

Se o sobressalto, como afirma Brum (2017), encarnou-se nos dias, a esperança não é apenas importante, mas imprescindível. Assim sendo, mediante pesquisa bibliográfica, visitou-se algumas obras de Paulo Freire para identificar aspectos de sua contribuição para que a educação cumpra seu papel libertador e que, portanto, ajude a devolver a esperança, 
VIEIRA, Luis Duarte; MALACARNE, Maicon André; ROSA, Cleci Teresinha Werner da; Esperança: tarefa

sobretudo em tempos muitos confusos e sofridos. E muitos são os aspectos que podem ser mencionados da vida e da obra de Paulo Freire nesse sentido. Mas, destacam-se os que seguem, a partir, sobretudo, das obras Pedagogia da Esperança e Pedagogia da Autonomia.

Na obra Pedagogia da Esperança, Freire afirma que "há uma esperança, não importa que nem sempre audaz, nas esquinas das ruas, no corpo de cada uma e cada um de nós" (2019, p.14). Essa afirmação ajuda a compreender que a esperança ainda reside em nós, mesmo quando não a percebemos ou quando ela parece fraquejar. Assim sendo, a escola como espaço vital para crianças, adolescentes, jovens e educadores pode ser espaço e lugar para alimentar essa esperança. "A esperança é uma necessidade ontológica” (Freire, 2019, p.14), e como tal a escola precisa contribuir no cuidado dessa necessidade.

Ao mesmo tempo, Freire reconhece que não é possível "negar a desesperança" (2019, p.14). O autor recorda que é preciso conhecer as "razões históricas, econômicas e sociais" (2019, p.14.) que explicam essa desesperança. Assim posto, fica evidente que a escola é convidada a gestar processos para que, em sua trajetória, os sujeitos que ali se encontram identifiquem essas razões. Em tempos de pandemia e pós-pandemia, é preciso olhar atento para compreender esse contexto e a desesperança que vai se fortalecendo, sobretudo com tantas perdas e mortes.

Freire ainda salienta que "como programa, a desesperança nos imobiliza e nos faz sucumbir ao fatalismo em que não é possível juntar as forças” (2019, p.14). Ora, os tempos da pandemia fortalecem a desesperança. Estar diante de tantas mortes, perdas e sofrimentos gera muita desesperança. Mas esta é também um projeto, um programa. E não podemos abraçar esse programa. Pelo contrário, precisamos tomar consciência e enfrentá-lo. A escola, nessa direção, tem a tarefa de ajudar a tomar consciência e nomear esse estatuto da desesperança, seja em tempos de pandemia seja em tempos de não pandemia. E, sobretudo, a escola precisa contribuir para juntar as forças em processos e caminhos que devolvam a esperança.

Freire, sempre lúcido e profético, recorda que:

Minha esperança é necessária, mas não é suficiente. Ela, só, não ganha a luta, mas sem ela a luta fraqueja e titubeia (...). Pensar que a esperança sozinha transforma o mundo e atuar movido por tal ingenuidade é um modo excelente de tombar na desesperança, no pessimismo, no fatalismo. Mas prescindir da esperança na luta para melhorar o mundo (...) é frívola ilusão. (...) A esperança precisa ancorar-se na prática. (...) A esperança precisa da prática para tornar-se concretude histórica. (2019, p.15) 
VIEIRA, Luis Duarte; MALACARNE, Maicon André; ROSA, Cleci Teresinha Werner da; Esperança: tarefa

Assim sendo, a escola, como lugar que alimentará a esperança e juntará forças para enfrentar o programa da desesperança, precisa de ação, de prática. Necessita encarnar-se na realidade que vive e ajudar, pouco a pouco, a transformar o mundo. Muitas são as práticas possíveis e que vem ocorrendo nas escolas nesse momento de pandemia. Muitas são as práticas que precisam ganhar força em nossas escolas Brasil afora.

Freire ainda enfatiza que "uma das tarefas do educador ou educadora progressista (...) é desvelar as possibilidades, não importam os obstáculos, para a esperança” (2019, p.16). Sendo tarefa dos educadores, é tarefa da escola. Apesar da pandemia e do sofrido contexto político, econômico e social que assola o país, é preciso encontrar possibilidades para devolver a esperança. Não se trata necessariamente de grandes processos, mas de pequenas ações, gestos e reflexões que, pouco a pouco, contribuam com a vida das pessoas que estão na comunidade escolar e, portanto, ajudem a (re)abastecer a esperança.

Freire (2019) ainda recorda que sem amor e sem raiva não há esperança. A escola que se compromete com a tarefa da esperança é uma escola que gera processos de amor e de raiva. Raiva do que mata, oprime, violenta. Amor para com as pessoas e suas histórias, a casa comum, a vida. Raiva das discriminações e da necropolítica. Amor entre as pessoas que compõe a comunidade escolar e dessa com toda a comunidade local.

Na obra Pedagogia da Esperança (2019), Freire narra as perguntas e afirmações que recebeu de um operário, em uma de suas palestras, e como isso foi importante em sua trajetória de vida e profissional. Em determinado momento da narrativa, Freire conta que o senhor em questão the indagou se ele sabia onde as pessoas que ali estavam moravam ou se ele já tinha estado na casa de algum dos operários pobres dali. A mesma pergunta pode ser feita aos educadores de todo o país hoje: sabemos onde vivem nossos estudantes? Já fomos à casa de alguns deles? A escola não gerará esperança e não unirá forças para enfrentar a desesperança se sequer souber onde vivem seus estudantes.

Ainda sobre essa temática, esse importante educador, lembra que:

Respeitar os educandos, porém, não significa mentir a eles sobre meus sonhos, dizer-lhes com palavras ou gestos ou práticas que o espaço da escola é um lugar "sagrado" onde apenas se estuda e estudar não tem nada que ver com o que se passa no mundo lá fora; esconder deles minhas opções, como se fosse "pecado" preferir, optar, romper, decidir, sonhar. (Freire, 2019, p.108)

Verifica-se, portanto, que o educador não pode relacionar-se com os discentes e com aquilo que ensina numa perspectiva de separação entre o que é vivido e aquilo que é estudado. 
VIEIRA, Luis Duarte; MALACARNE, Maicon André; ROSA, Cleci Teresinha Werner da; Esperança: tarefa

Uma escola não combaterá o programa da desesperança e tampouco devolverá esperança, sobretudo nesse tempo, se não reconhecer que é preciso refletir, abordar, conhecer "o que se passa no mundo". Não haverá esperança se a escola gerar processos que fecham os olhos para a realidade que se vive.

Freire também afirma que em determinado momento de sua trajetória de vida inventou "a esperança concreta em que um dia me livraria de meu mal-estar" (2019, p.42) Em tempos de pandemia e de tantas mortes e perdas, é preciso inventar esperança concreta que gere movimento, ação. A escola pode ajudar seus estudantes a inventar uma esperança concreta de um mundo sem tantas perdas e mortes, de um mundo sem tanta negação de direitos.

Discorrendo sobre as tarefas da educação democrática e popular, Freire recorda que uma dessas tarefas é:

Possibilitar nas classes populares o desenvolvimento de sua linguagem, jamais pelo blablablá autoritário e sectário dos "educadores", de sua linguagem, que, emergindo da e voltando-se sobre sua realidade, perfile as conjecturas, os desenhos, as antecipações do mundo novo. Está aqui uma das questões centrais da educação popular - a da linguagem como caminho de invenção dacidadania. (2019, p.56)

Verifica-se, portanto, que a educação que gera esperança é necessariamente a educação que contribui concretamente para a cidadania, partindo da realidade, refletindo-a e ajudando a transformá-la. Nesse movimento, as pessoas dão sentindo ao que estudam e isso vai derrotando o projeto da desesperança. Além dessa tarefa, Freire enfatiza que:

Uma das tarefas da educação popular progressista, ontem como hoje, é procurar, por meio da compreensão crítica de como se dão os conflitos sociais, ajudar o processo no qual a fraqueza dos oprimidos se vai tornando força capaz de transformar a força dos opressores em fraqueza. Esta é uma esperança que nos move. (2019, p.14)

Ainda, sobre as mudanças necessárias na sociedade, Freire recorda que "a recusa à ideologia machista, que implica necessariamente a recriação da linguagem, faz parte do sonho possível em favor da mudança do mundo" (2019, p.94.) É preciso reafirmar que não haverá a total derrota do programa da desesperança se não houver a derrota da ideologia machista. Essa ideologia, que assume tantas formas e que na pandemia viu crescer o número de casos de violência contra as mulheres, precisa ser derrotada, e a escola tem um papel fundamental nesse processo, tanto na conscientização, como na formação e também na ação. Uma escola 
VIEIRA, Luis Duarte; MALACARNE, Maicon André; ROSA, Cleci Teresinha Werner da; Esperança: tarefa

comprometida com a superação da violência contra as mulheres é uma escola que gera esperança.

Freire ainda salienta que não haverá educação democrática, revolucionária ou geradora de esperança se os educadores não forem fiéis aos seus sonhos e respeitarem seus estudantes. Para tal, segundo o autor, é preciso que os educadores não “os manipulem” (2019, p.111). Verifica-se que se houver manipulação e falta de respeito não haverá esperança.

Refletindo sobre sua prática como educador, Freire questionou-se: "que educador seria eu se não me sentisse movido por um forte impulso que me faz buscar, sem mentir, argumentos convincentes na defesa dos sonhos por que luto?” (2019, p.117.). Essa indagação leva-nos a pensar sobre a escola como local que precisa ajudar a sonhar e a lutar para fazer o sonho ser realidade. Fica mais que evidente, sobretudo em tempos de tantos lutos, que uma escola que gera esperança é aquela que leva a sonhar e a lutar pelos sonhos. Como afirma Freire:

Fazendo-se e refazendo-se no processo de fazer a história, como sujeitos e objetos, mulheres e homens, virando seres da inserção no mundo e não da pura adaptação ao mundo, terminaram por ter no sonho também um motor da história. Não há mudança sem sonho como não há sonho sem esperança. (2019, p.26)

Ainda sobre a importância do sonho para gerar esperança e transformar a realidade, o autor lembra que:

\footnotetext{
Do ponto de vista dos interesses das classes dominantes, quanto menos as dominadas sonharem o sonho (...), quanto menos exercitarem a aprendizagem política de comprometer-se com uma utopia, quanto mais se tornarem abertas aos discursos "pragmáticos", tanto melhor dormirão as classes dominantes. (Freir, 2019, p.127)
}

Uma escola que gera esperança é uma escola que não deixa as classes dominantes dormirem em paz, porque é uma escola que gera sonhos e coloca as pessoas em movimento para realizá-los.

Freire infere que:

Ensinar exige alegria e esperança $\mathrm{O}$ meu envolvimento com a prática educativa, sabidamente política, moral, gnosiológica, jamais deixou de ser feito com alegria, o que não significa dizer que tenha invariavelmente podido criá-la nos educandos. Mas, preocupado com ela, enquanto clima ou 
atmosfera do espaço pedagógico, nunca deixei de estar. Há uma relação entre a alegria necessária à atividade educativa e a esperança. (1996, p.29)

Segue o autor explicitando que não há esperança se não há alegria, não há alegria sem esperança. E não há educação que não exija alegria e esperança. Em tempos de tantos lutos e sofrimentos, resgatar a alegria é um grande desafio. E é um desafio que vale a pena ser enfrentado. Sem dúvida alguma, uma escola que ajude a devolver alegria aos educandos é uma escola que gera esperança.

Freire, na obra Pedagogia da Autonomia, pontua que:

Mulheres e homens se tornaram educáveis na medida em que se reconheceram inacabados. Não foi a educação que fez mulheres e homens educáveis, mas a consciência de sua inconclusão é que gerou sua educabilidade. É também na inconclusão de que nos tornamos conscientes e que nos inserta no movimento permanente de procura que se alicerça a esperança. (1996, p.23)

Tomar consciência dessa inconclusão, sobretudo nesses tempos de pandemia, permitirá esse movimento da busca, ou seja, esse movimento da esperança. Tecer a escola nessa consciência da incompletude e inconclusão romperá a postura fechada e autoritária do conhecimento como pronto e como desconexo da vida e da realidade, porque coloca a pessoa em movimento, em busca. Mas nessa busca esperançosa.

\section{Considerações finais}

É preciso ter esperança. Mas tem de ser esperança do verbo esperançar. Por que tem gente que tem esperança do verbo esperar. Esperança do verbo esperar não é esperança, é espera. "Ah, eu espero que melhore, que funcione, que resolva". Já esperançar é ir atrás, é se juntar, é não desistir. É ser capaz de recusar aquilo que apodrece a nossa capacidade de integridade e a nossa fé ativa nas obras. Esperança é a capacidade de olhar e reagir àquilo que parece não ter saída. Por isso, é muito diferente de esperar; temos mesmo é de esperançar! (Freire, 2019)

A esperança, de esperançar e não de esperar, é urgente e necessária, sobretudo nesse tempo da pandemia da Covid-19. Ou teremos esperança ou sucumbiremos ao desespero. Paulo Freire, grande educador brasileiro, recorda que "ninguém chega a parte alguma só" (2019, p.43). E o afirma corretamente. Ninguém chega a parte alguma só. Assim sendo, a educação só cumprirá seu papel de gerar esperança e ser libertadora se abraçarmos 
VIEIRA, Luis Duarte; MALACARNE, Maicon André; ROSA, Cleci Teresinha Werner da; Esperança: tarefa

coletivamente essa tarefa. Juntos e juntas poderemos derrotar o programa da desesperança e inventar esperanças concretas, históricas feitas de ação e prática cotidiana, com raiva e amor. É preciso seguir, como afirmava Dom Paulo Arns, em seu lema episcopal, de Esperança em Esperança. 
VIEIRA, Luis Duarte; MALACARNE, Maicon André; ROSA, Cleci Teresinha Werner da; Esperança: tarefa

\section{Referências bibliográficas}

BOGDAN, Robert; BIKLEN, Sari. Investigação qualitativa em educação. Portugal: Porto, 1994.

BRUM, Eliane. Cotidiano de Exceção. El País. 2017. Disponível em: $<$ https://brasil.elpais.com/brasil/2017/05/29/opinion/1496068623_644264.html>. Acesso em: 25 abr 2021.

FREIRE, Paulo. Pedagogia da Autonomia. 25.ed. São Paulo: Paz e Terra, 1996.

FREIRE, Paulo. Pedagogia da Esperança. 26.ed. São Paulo / Rio de Janeiro: Editora Paz e Terra, 2019.

GIL, Antonio Carlos. Como elaborar projetos de pesquisa - 4.ed. São Paulo: Atlas, 2002, 